\title{
Aquatic Transitions Working Group
}

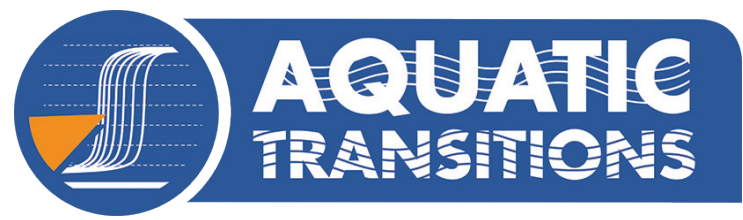

\author{
Peter Gell1, J.A. Dearing 2 , S. Juggins ${ }^{3}$, M.-E. Perga ${ }^{4}$, J. Saros ${ }^{5}$ \\ and C. Sayer ${ }^{6}$
}

Wetlands and water remain a key realm of applied paleoecological research with many proxies reflecting the changing status of the water body as well as reflecting the climatic and human drivers of these changes. This working group will review direct human impact on aquatic ecosystems at times in the past critical to each region and the internal ecological shifts of the wetlands, to explore the responsiveness, resistance, and resilience of aquatic systems worldwide to natural and anthropogenic forces.

Human activities have impacted greatly on global aquatic systems through the release of pollutants and the regulation and abstraction of surface and groundwater. This has, and will continue to impact critically on ecosystem productivity with further consequences for human well being. Simultaneously, aquatic systems have responded to long and shorter-term variations in temperature and effective precipitation.

Many of these responses have been non-linear, with aquatic ecosystems both responding abruptly, and showing a certain level of resilience to forces until a threshold is breached. Wetlands are a classic ecosystem used to demonstrate alternative stable states whereby feedbacks can act to resist pressures, but also act to entrench the system in a new state once pressures force a regime shift.

Many of the changes witnessed, or modeled, by ecologists have existed in the past. Accordingly, research on major transitions in aquatic systems represents a significant field of enquiry that demands contribution from both contemporary ecology and paleoecology. Further, long term records of change provide evidence of the ecosystem dynamics that may have occurred leading up to a threshold change and, thereby, can reveal early warning signals that may be lessons to prioritise intervention measures for future management.

\section{Scientific goals and activities}

The Aquatic Transitions Working Group has two principal charters or projects. The first is to document the global history of the impact of humans on aquatic systems. By identifying the first point of human impact and the inception and peak of the impact of the industrialised phase, Project 1 will reveal the responsiveness of aquatic systems to the presence of humanity, within a framework of climate variability. Project 2 will drill down into the nature of these transitions to examine the ecosystem dynamics that have

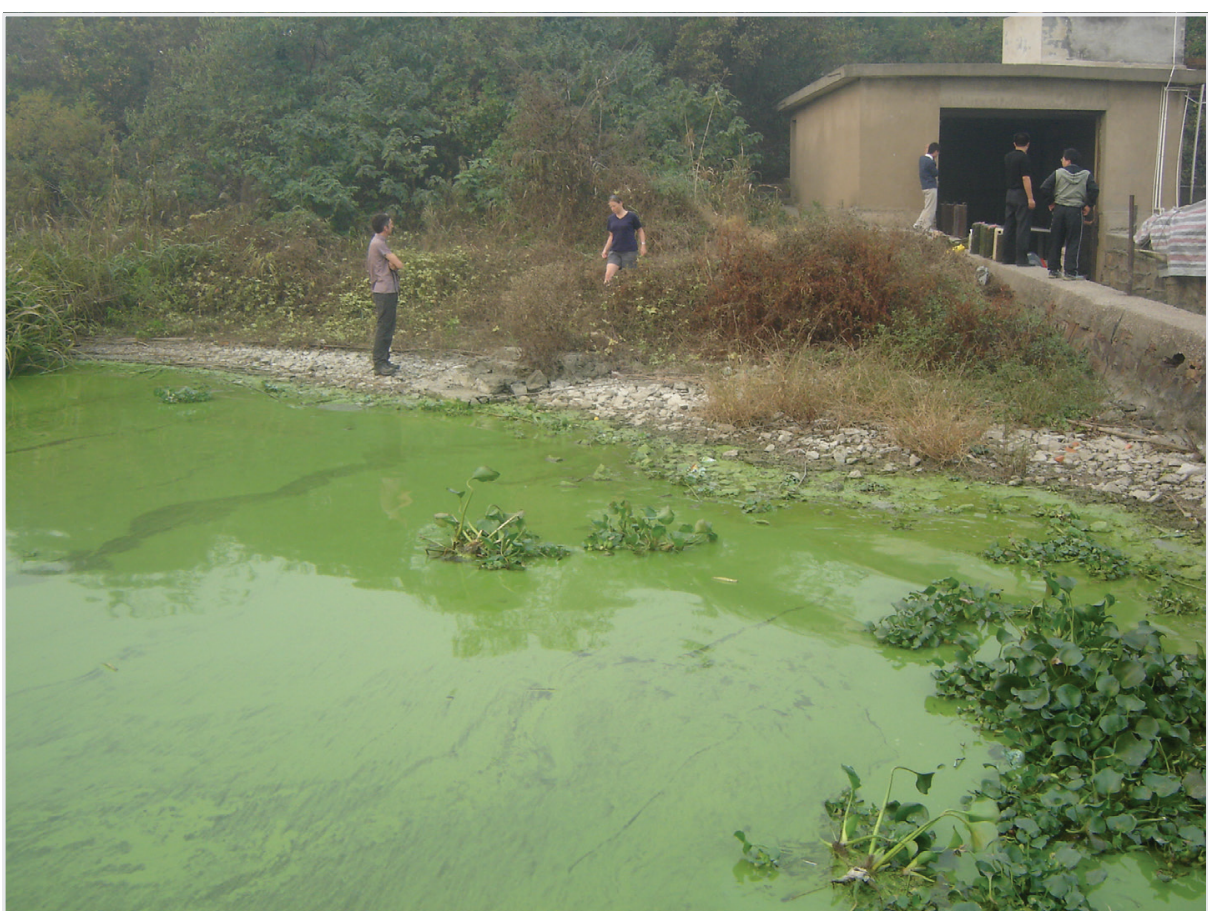

Figure 1: Taihu Lake, on the southern part of the Yangtze River delta, is the third largest freshwater lake in China. Taihu became eutrophic following intensive development from the 1980s and has been covered by an extensive Microcystis bloom since the late 1990s. Understanding the nature of aquatic transitions provides insights for the challenge of wetland restoration. resisted human pressures, as well as the changes leading up to the point where the system succumbed, and the degree to which new, stabilising forces have entrenched the system in a new regime.

Aquatic Transitions will achieve these goals by collating published global paleohydrological and paleoecological records, sifting through these records and attributing changes in records to critical phases in human settlement and activity. It will select critical points of impact that may be time transgressive. By focussing its research on these points of transition, the working group will apply established ecological reason to attribute the identified changes to press or pulse responses or regime shifts. Thus it will respond directly to several key questions in paleoecology as identified at the PAGESsupported Palaeo50 workshop in 2012 (Seddon et al. 2014).

Aquatic Transitions seeks representation from across the globe and will use meetings to assemble a global database, use change point analysis to identify timing and cause of change, synthesize records at continental and global scales, and write outputs.

Visit the Aquatic Transitions website at: www.pages-igbp.org/workinggroups/aquatic-transitions

and sign up to our mailing list to keep up to date with our activities.

\section{Upcoming activities}

The first meeting of the Aquatic Transitions Working Group will be in Keyworth, UK, 22-24 April 2015, and there will be a follow up workshop on 3 August 2015 in association with the International Paleolimnology Congress in Lanzhou, China.

\section{AFFILIATIONS}

${ }^{1}$ Water Research Network, Federation University Australia, Ballarat, Australia

${ }^{2}$ Geography and Environment, Southampton University, UK

${ }^{3}$ Geography, Newcastle University, UK

${ }^{4}$ Institute national de la recherche agronomique, Paris, France

${ }^{5}$ Climate Change Institute, University of Maine, USA ${ }^{6}$ Environmental Change Research Centre, University College London, UK

\section{CONTACT}

Peter Gell: p.gell@federation.edu.au

\section{REFERENCE}

Seddon et al. (2014) J Ecol 102: 256-267 